\title{
Results of using an electric drive platform for harvesting strawberries
}

\author{
Rostislav Filippov*, Stepan Semichev and Roman Vershinin \\ Federal Scientific Agroengineering Center VIM, 1-st Institutsky proezd, 5, Moscow, 109428, Russia.
}

\begin{abstract}
The most common and cost-effective berry crop in the Russian Federation is strawberry garden. A feature of the cultivation of this crop is the increased labor costs, which reach up to 2000 people $\cdot h / h a$, a large share of which is accounted for by manual harvesting operations. In this connection, the creation and use of an electric drive platform for the cultivation and harvesting of strawberries on an industrial plantation will significantly reduce labor costs, increase productivity and reduce the degree of labor fatigue in gardening. As a result of the conducted research, data on the effectiveness of the use of an electric drive platform for the operation of harvesting strawberries in the conditions of an industrial plantation of "Sovhoz imeni Lenina", so the productivity of harvesting strawberries increased by an average of $34.2 \%$. The quality of the technological process of harvesting berries for the entire period of use of the platform was at the level of the usual manual harvesting. The completeness of the harvesting ranged from $95.8 \%$ in heavily thickened rows with a large number of weeds, to $99.5 \%$ in areas with good agricultural techniques for maintaining plantings and it is economically feasible to use an electric platform with a yield of more than $30 \mathrm{c} /$ ha.
\end{abstract}

\section{Introduction}

Horticultural is a specific branch of Russian agriculture that provides the country's population with fresh fruits and berries. However, the annual production of fruits and berries in farms of all categories in Russia is at the level of 3.4 million tons, and imports are more than 2 million tons $[1,2]$, but this figure is $40 \%$ lower than the recommended annual consumption of fresh fruit. One of the reasons for this situation is the high labor costs of cultivating garden crops, especially for harvesting processes, the level of mechanization of which remains extremely low. Technical means that facilitate the work of workers when harvesting strawberries have been used for a long time. Since the beginning of the $60 \mathrm{~s}$ of the last century, work has been carried out to simplify manual labor, for which various devices were created - from the simplest to complex self-propelled platforms. In each period of time, the created technical means solved actual problems for their time, as they were used as technical innovations. This confirms the expediency of the developments carried out in this direction. At the present stage of development of equipment and technologies, it is possible to design and manufacture any machine, including the most

*Corresponding author: rostislav-filippov@yandex.ru 
complex. However, the question arises about the expediency and economic validity of this work, which should be evaluated by the complex criterion "cost-effectiveness" $[3,4]$. To improve the operation of collecting berries for use in medium and large berry farms, the specialists of the FSAC VIM developed an electric drive platform.

\section{Materials and Methods}

The paper uses generally accepted methods of mathematical processing of experimental data. To study the effectiveness of the labor process of picking berries and other parameters of human activity in the process of harvesting berries, we used the method of observation, time-lapse studies, as well as accounting for the number of berries harvest per unit of time and the overall quality of the technological operation. The main results of the experiments were processed using standard computer programs. The physiological state of the collector was measured by measuring the heart rate, the pulse was measured by an automatic heart rate monitor sigma 15.11 .

\section{Results and Discussion}

Harvesting of strawberries with the use of an electric drive platform was carried out on an industrial plantation of strawberries of the garden variety "Malvina" in «Sovhoz imeni Lenina» (Moscow region, Leninsky district). The harvest was carried out in the period from 08.07.2019 to 02.08.2019. The productivity of manual harvesting directly depends on such factors as the size of the berries and their weight. From the data in (Table 1), it can be seen that in the initial period (1-3 harvests), the berries are the largest and their number is less, but the number of berries on the bush is the dominant factor and therefore the productivity of the worker increases.

Table 1. Some parameters of berries in different harvest periods.

\begin{tabular}{|c|c|c|}
\hline \multirow[b]{2}{*}{ № } & \multirow[t]{2}{*}{ Parameter } & Grade \\
\hline & & Malvina \\
\hline 1 & $\begin{array}{l}\text { Average weight of the berry in the initial } \\
\text { harvest period, g. }\end{array}$ & 18,3 \\
\hline 2 & $\begin{array}{l}\text { Average weight of berries in the middle of the } \\
\text { harvest, g. }\end{array}$ & 17,4 \\
\hline 3 & $\begin{array}{l}\text { Average weight of berries in the final harvest } \\
\text { period, g. }\end{array}$ & 13,3 \\
\hline 4 & $\begin{array}{l}\text { the average number of berries in the initial } \\
\text { period, pcs./ p. m. }\end{array}$ & 9,3 \\
\hline 5 & -in the middle of the harvest, pcs./ p. m. & 23,6 \\
\hline 6 & - in the final period, pcs./ pog. m. & 16,4 \\
\hline
\end{tabular}

To increase the productivity of manual labor, reduce the loss of time for carrying empty and full containers, and reduce fatigue, the specialists of the FSAC VIM developed a single-seat platform with an electric drive (Fig. 1), (Fig. 2). 


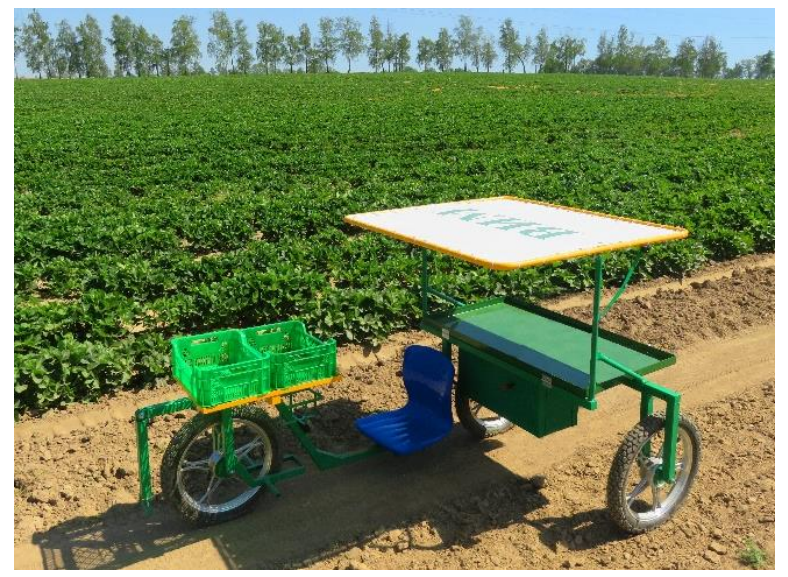

Fig. 1. Electric drive platform (side view).

Table 2. Main technical characteristics of the platform with an electric drive for harvesting operations in berry growing.

\begin{tabular}{|c|l|c|}
\hline № & \multicolumn{1}{|c|}{ Main parameters } & Value \\
\hline 1 & Curb weight, $\mathrm{kg}$ & 85 \\
\hline 2 & Load capacity, $\mathrm{kg}$ & 200 \\
\hline 3 & Wheel diameter, $\mathrm{mm}$ & 550 \\
\hline 4 & Drive wheel torque, $\mathrm{Nm}$ & 60 \\
\hline 5 & Agrotechnical clearance, $\mathrm{mm}$ & 600 \\
\hline 6 & Driving speed, $\mathrm{km} / \mathrm{h}$ & до 4,5 \\
\hline 7 & Power of the drive motor, $\mathrm{W}$ & 500 \\
\hline 8 & Battery capacity, Ah & 108 \\
\hline 9 & Power supply voltage, $\mathrm{V}$ & 24 \\
\hline 10 & Motion control panel & Joystick \\
\hline
\end{tabular}

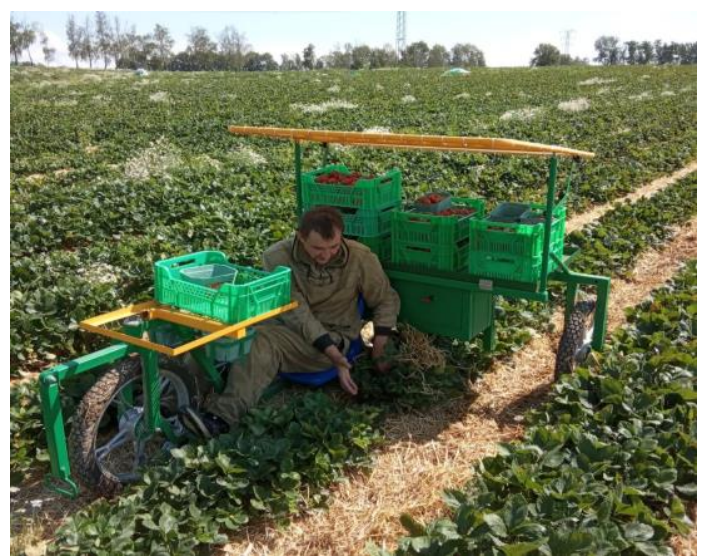

Fig. 2. The process of harvesting strawberries on an electric drive platform.

On the graph (Fig.3) shows the change in productivity when using an electric platform and without it, depending on the yield at the time of harvest.The analysis of this graph shows that the use of the platform at the very beginning of the season with a yield of up to $20 \mathrm{c} /$ ha does not increase productivity compared to manual harvesting without the use of the platform. The predominance in productivity using the platform can be observed with a yield at the time of harvest of $30 \mathrm{c} /$ ha or more. Thus, with a yield of $50 \mathrm{c} / \mathrm{ha}$, the 
productivity with the use of the platform was $9.5 \mathrm{~kg} / \mathrm{h}$, and without the use of $6.8 \mathrm{~kg} / \mathrm{h}$, the productivity growth was $31 \%$, and with a yield of $100 \mathrm{c} /$ ha, the productivity growth was already $39 \%$. The increase in productivity is due to the fact that when working on the platform, workers are in more comfortable conditions, the harvest is carried out in a sitting position on a swivel seat, alternately from two rows, which makes it necessary to make small leans to the left and right within 10 degrees, which according to labor protection standards does not have a negative impact on a person. The picker has a sufficient supply of empty containers for the entire working day, and also transports the harvested crop during the harvest, thereby reducing the travel area on the plantation, while eliminating the time spent on carrying the harvested crop.The analysis of time-based observations of the harvesting process during the entire working day showed that with normal manual harvesting without the use of technical means, good productivity indicators are achieved in the morning, but by the end of the shift they decrease due to the influence of difficult working conditions on a person. On the contrary, working on a single electric platform during a full working shift confirms stable performance due to the fact that the picker in the sitting position is less tired, spends less energy on movement, and most of the time is engaged in harvesting.

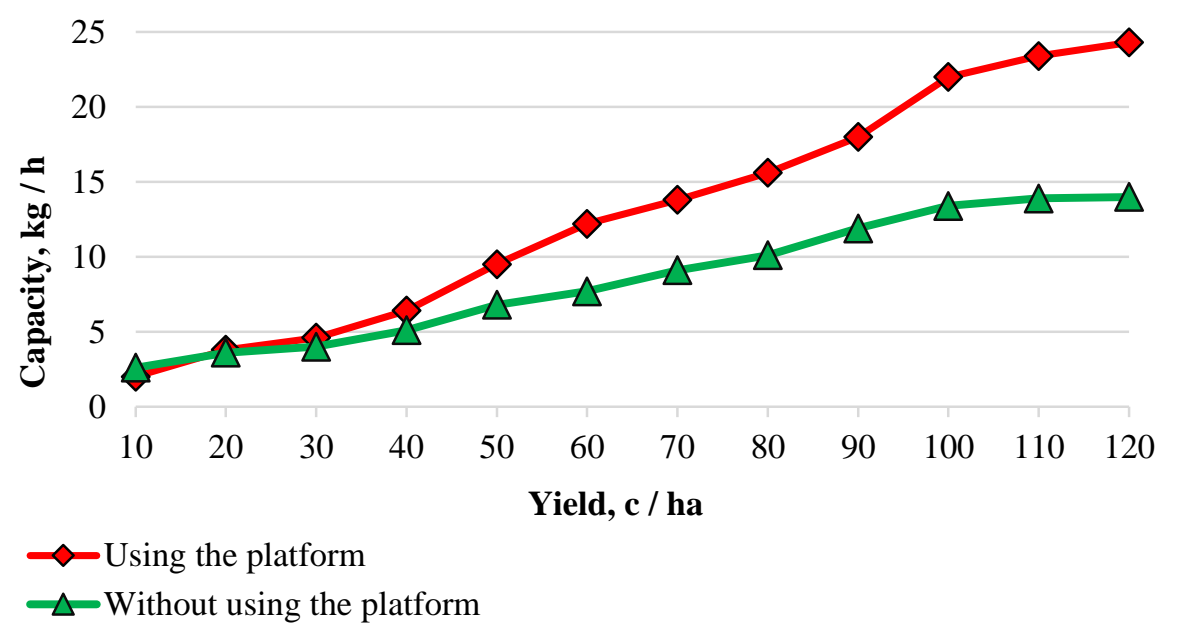

Fig. 3. Graph of the dependence of the productivity of berry harvesting on the yield of strawberries when using an electric drive platform and without it.

To determine the degree of general physical activity, the changes in the heart rate of the employee during the berry picking process were measured. Using the Sigma 15.11 pulse meter, the change in the pulse of pickers during harvesting with and without an electric drive platform was evaluated. The pulse was recorded every 30 minutes of operation. A comparative characteristic of the obtained data is shown in the graph (Fig. 4), from which it can be seen that when working with the use of an electric drive platform, the pulse is at rest, and when harvesting without the use of the platform, the heart rate was higher on average by 11-22 beats per minute than when working with the use of the platform. 


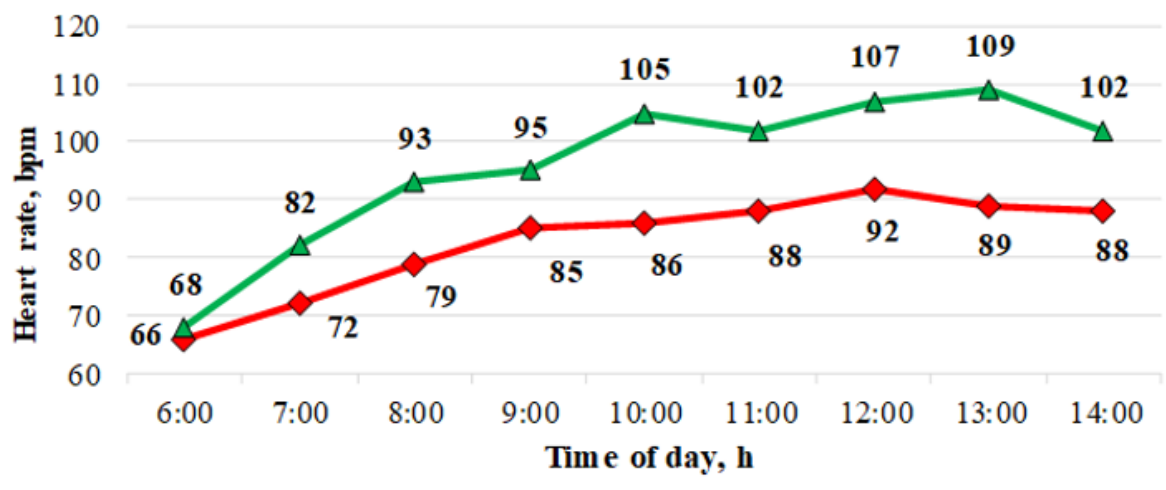

$\neg$ Using the platform

$\triangle$ Without using the platform

Fig. 4. The average value of the collector's heart rate when using the platform and without it.

\section{Conclusions}

The quality of the technological process of harvesting berries for the entire period of use of the platform was at the level of the usual manual harvest. The completeness picking ranged from $95.8 \%$ in heavily thickened rows with a large number of weeds, to $99.5 \%$ in areas with good agricultural techniques for maintaining plantings. The analysis of the obtained data showed that as a result of the use of an electric drive platform, the productivity of harvesting strawberries increased by an average of $34.2 \%$ and it is economically feasible to use an electric drive platform with a yield of more than $30 \mathrm{c} /$ ha. The increase in labor productivity is associated with a reduction in the time spent on the delivery of containers, the removal of products, the movement of containers, the necessary rest time, as well as due to less stressful working conditions. The platform with an electric drive is intended to be used in other works carried out on an industrial strawberry plantation - planting and weeding. When harvesting without the use of the platform, the heart rate was higher by an average of 11-22 beats per minute than when working with the use of the platform, which indicates a significant fatigue of the labor process.

\section{References}

1. Y. Xiong, C. Peng, L. Grimstad, P. Johan From, V. Isler, Development and field evaluation of a strawberry harvesting robot with a cable-driven gripper, Computers and Electronics in Agriculture, 157, pp 392-402, (2019)

2. Kulikov I.M., Utkov Yu.A., Buchkov V.V. Technical equipment of modern industrial gardening and prospects of its improvement. Agricultural machines and technologies. 5, pp 3-8. (2010)

3. Utkov Yu.A., Chyhlyaev I.I. The modern world trends and the development of mechanization in the cultivation of crops for intensive technologies of industrial plantations in Russia. Collection of scientific reports of the International scientific and technical conference dedicated to the 145th anniversary of academician V. P. Goryachkin. Pp 230235. (2013)

4. Filippov R.A., Khort D.O., Smirnov I.G. Substantiation of the parameters constructions platform with electric drive for harvesting strawberries// E3S Web of Conferences 126, pp 1-9 (2019) 